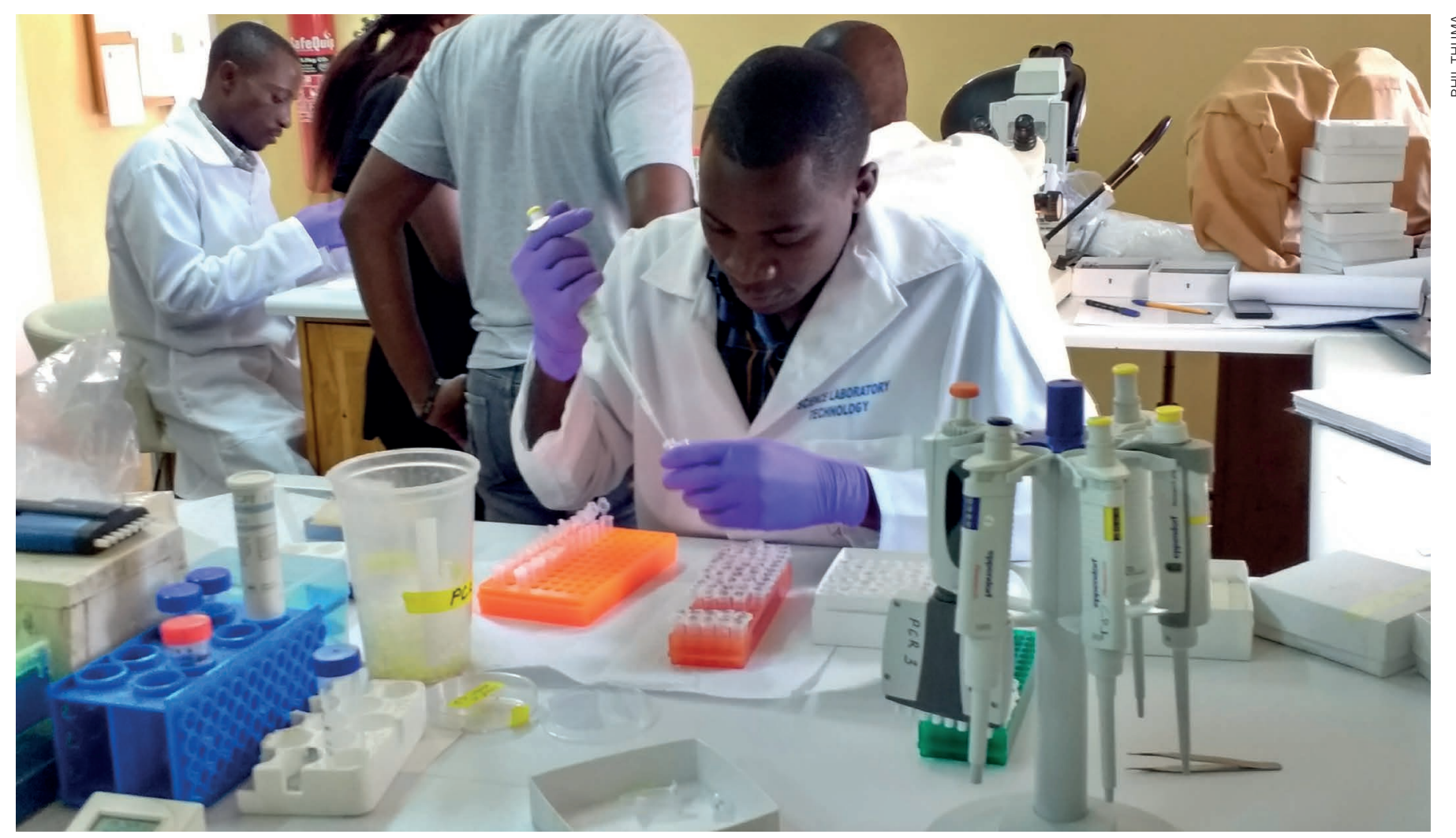

Researchers at the Macha Research Trust have made strides in tackling malaria in southern Zambia.

COMMUNITIES

\title{
A matter of trust
}

\section{Improving health in low-and middle-income countries requires earning the confidence of the local community, one relationship at a time.}

\section{BY LUCAS LAURSEN}

$\mathrm{H}$ ealth researchers and workers use their training and the treatments available to them to prevent and treat illness. But they cannot bring their expertise to bear if they do not have the trust of the people that they are trying to treat.

This August, in the Democratic Republic of the Congo, communities in the midst of an Ebola outbreak continued traditional rural burial practices that include touching bodies, despite health workers' advice on sanitary burials. Residents in the village of Manbangu burnt down a health centre and injured an Ebola health-care worker after one resident died of Ebola. Sometimes fear and misinformation drive even more violent behaviour: in a 2014 outbreak of the disease in Guinea, residents of the village of Womey killed a group of eight visiting health workers, journalists and government officials.

A community's trust is not something that can be bought, says Peter Agre, a Nobel prizewinning chemist turned malaria researcher at the Johns Hopkins Malaria Research Institute in Baltimore, Maryland. "You have to earn trust," he said at the 68th Lindau Nobel Laureate Meeting in Germany, earlier this year.

One place that seems to have built and maintained trust over many years, Agre says, is the Macha Research Trust near Choma in southern Zambia. The centre has lowered the number of cases of malaria in the surrounding area much faster than global incidence rates have declined. It works with international partners, national and local authorities and the local community. Building up those partnerships relied on individuals who were willing to make a commitment to each other and the cause.

\section{GLOBAL TALENT, LOCAL RELATIONSHIPS}

Malaria researcher Sungano Mharakurwa had a tough decision to make in 2003 when he finished his postdoctoral fellowship at the University of Oxford, UK. He had developed new diagnostic tests for the disease, and would have been a promising candidate for a research post anywhere in the world. $\mathrm{He}$ wanted to go home to Zimbabwe, however, but his postdoc supervisor urged him to avoid the country, which was experiencing a general strike, political turmoil and a severe economic crash. "She was basically telling me I should not even think of going back," he recalls.

It was then that Mharakurwa saw an advertisement for a position to establish a malaria research centre at the Macha Mission Hospital in neighbouring Zambia, in collaboration with Johns Hopkins University in Baltimore, Maryland. The centre could not compete with the salary that Mharakurwa might have earned abroad. But what it could offer him was an opportunity to use his knowledge and network of international contacts on malaria's front line.

The Macha hospital was founded by Alvan and Ardys Thuma, husband-and-wife medical missionaries from the United States, in 1957. Agre is critical of certain medical missionaries and international agencies that rotate their staff too frequently to build up the long-term trust and knowledge that is needed to implement the best science-informed policies. Some 

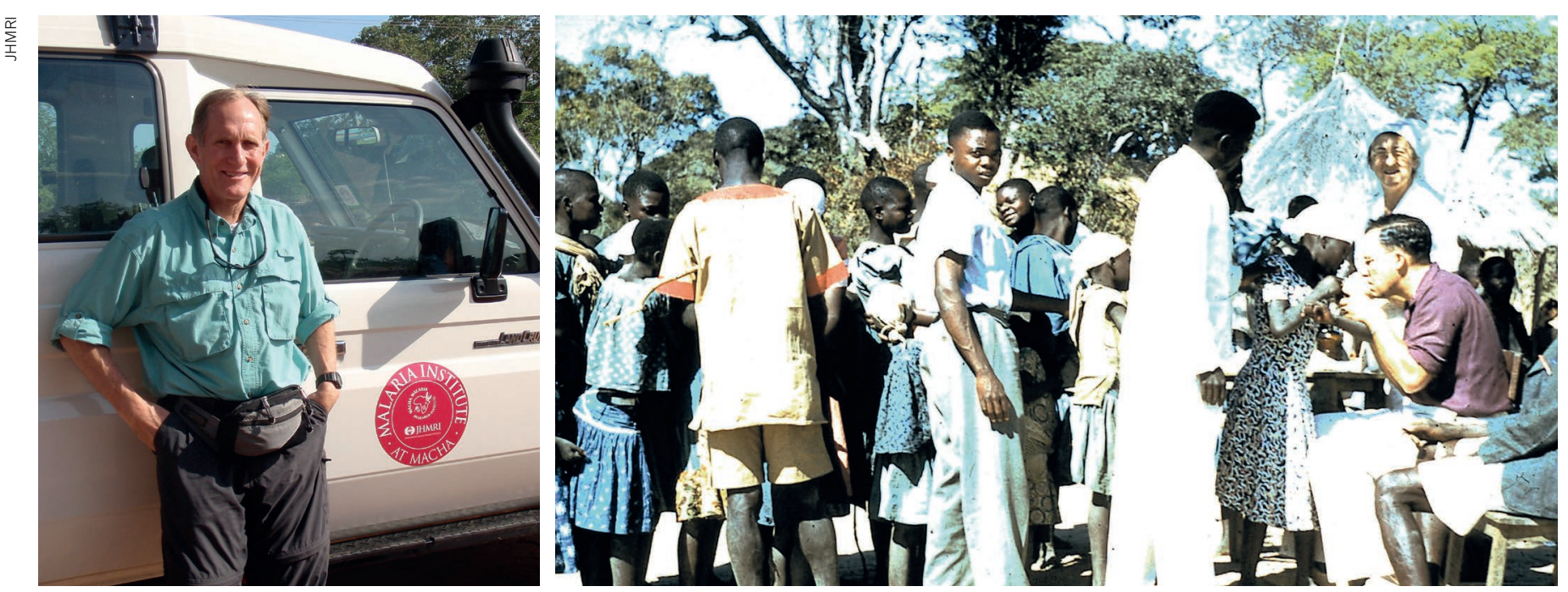

Peter Agre (left) says Macha Mission Hospital is an example of how trust is built over time. One of its founders (Alvan Thuma; right) worked in Africa for 20 years.

international health missions have such a high staff turnover that "human trust is stretched thin," Agre says. This was not the case for Macha. "[The Thumas] stayed there longer than many Zambians," Mharakurwa says. They established a long-standing rapport with the local community and national officials. Their son, Philip Thuma, who is also a doctor, helped to establish the research centre at Macha and is still working there. By those standards, Mharakurwa, who now has an administrative post at Africa University in Mutare, Zimbabwe, but is still doing research at Macha, is a relative newcomer, with 15 years under his belt.

The continuity of staff is just one reason why Macha's approach is respected by the local community. Several other important decisions have helped to gain and sustain trust. One is to hire locally. A local chief was resistant to the mission until his son started volunteering in the Macha labs. "He was able to bring his father to come and see the labs and the blood samples. And they loved it," Mharakurwa says. "The community, they feel that they are stakeholders. Their children are actually working at this institute; they have a sense of ownership," he adds.

Another strategy is to take the time to explain new studies so that community members have a high, if non-technical, level of understanding of the risks and benefits. The scientists introduce research ideas to community leaders and then present them at wider gatherings so that the public can ask questions and decide whether to accept the study. As the meetings go on, Mharakurwa says, some community members end up answering other members' questions. "Then you know your study is accepted," he says.

Timing the introduction of new studies to the community is tricky. "The earlier, the better to involve the community, including in the design stage," Mharakurwa says. However, he adds, once a programme has been introduced, it must then materialize in a reasonable time frame, or else credibility might be lost and make future approaches more difficult.

Once a study is under way, it is also important for scientists to communicate to participants the benefits of getting involved, says Blessing Ahiante, a $\mathrm{PhD}$ researcher in the Hypertension in Africa Research Team (HART) at North-West University in Potchefstroom, South Africa. Ahiante does fieldwork on blood pressure, diet and genetics in rural and less educated communities in South Africa. She provides simplified educational materials for study participants to explain her research, and tries to give

$\begin{array}{ll}\text { "False rumours } & \begin{array}{l}\text { related advice that } \\ \text { they can start to use }\end{array} \\ \text { can ignite if } & \text { right away, before } \\ \text { with the } & \text { the study itself gives } \\ \text { community } & \text { results. "We've got } \\ \text { ispoor." } & \text { them to eat more } \\ & \text { beets," Ahiante says, } \\ & \text { as well as to reduce }\end{array}$
their salt intake, do more exercise and to drink more water, all of which will help to manage the growing burden of non-communicable diseases, such as diabetes, in poor communities (see page S65).

\section{ORGANIZING FOR HEALTH}

The Macha Research Trust also tries to provide local people with tangible benefits from its work. For example, on the basis of satellite imagery, the centre can detect probable mosquito breeding sites and warn nearby residents by text message. Such shortterm benefits encourage greater cooperation in subsequent studies, which enables the centre to do better science. For instance, it has begun to use the rapid diagnostics that Mharakurwa developed at Oxford to test for individuals carrying the malaria parasite at a dormant stage. Persuading busy people to allow researchers to test them when they were asymptomatic wasn't easy, but it might have contributed to successfully lowering malaria rates in the region.
Mharakurwa is now working to apply Macha's approach to research elsewhere, including his home country, Zimbabwe. "I believe what Macha does is really the right way of building trust with the community," he says.

"I hope he succeeds, but it's not a given," Agre says. "The governance of Zimbabwe has been unstable and the economy is severely stressed," he explains - factors that can disrupt public-health efforts.

Other health-care researchers and practitioners have experienced broken community trust for reasons that range from complacency to bad luck. In what must be the most extreme case, efforts to eradicate polio were subjected to years, if not decades, of delays in Pakistan after US intelligence operatives used health workers to assist in the hunt for al-Qaeda leader Osama bin Laden. The ploy has led to mistrust of vaccination drives and even occasional acts of violence against vaccine workers.

Events such as these have contributed to a growing awareness of the risks of research or implementation programmes, Mharakurwa says. "False rumours can ignite if communication with the community is poor," he adds.

The Macha approach is as an example of the sort of continuity and investment in human relationships that is needed if science is going to succeed in the poorest parts of the world. Solutions to malaria and many other diseases exist already, says Agre. The problem is that they are not available to the people who need them the most. The onus is on political leaders, he says, to properly allocate the resources needed - or to at least get out of the way of health-care workers. And organizations must win the co-operation of community members for both research and implementing interventions. "Organization is what improves health," Agre says, "We don't need to reach for magical cures." -

Lucas Laursen is a freelance journalist in Madrid. 